\title{
Boundary Layer Transition Protuberance Tests at NASA JSC Arc-Jet Facility
}

\author{
Max E. Larin", Jeremiah J. Marichalar ${ }^{\dagger}$ \\ Jacobs Technology, Houston, TX 77058, USA \\ Gerald R, Kinder ${ }^{\ddagger}$ \\ The Boeing Company, Huntington Beach, CA 92647, USA \\ Charles H. Campbell ${ }^{\S}$, Joseph R. Riccio ${ }^{* *}$, Tien Q. Nguyen ${ }^{\dagger \dagger}$, Steven V. Del Papa ${ }^{\ddagger \ddagger}$ \\ NASA Johnson Space Center, Houston, TX 77058, USA \\ and \\ Maria V. Pulsonetti ${ }^{\S}$ \\ NASA Langley Research Center, Hampton, VA 23681, USA
}

\begin{abstract}
A series of tests conducted recently at the NASA JSC arc-jet test facility demonstrated that a protruding tile material can survive the exposure to the high enthalpy flows characteristic of the Space Shuttle Orbiter re-entry environments. The tests provided temperature data for the protuberance and the surrounding smooth tile surfaces, as well as the tile bond line. The level of heating needed to slump the protuberance material was achieved. Protuberance failure mode was demonstrated.
\end{abstract}

\section{Nomenclature}

$\begin{array}{ll}B F & =\text { bump factor } \\ T & =\text { temperature } \\ k & =\text { protuberance height } \\ \delta_{B L} & =\text { boundary layer thickness } \\ \theta & =\text { momentum thickness }\end{array}$

\section{Introduction}

N important factor in assessing spacecraft re-entry aerothermal environments is the time of laminar to turbulent transition. Turbulent heating may be 3-5 times higher than laminar heating. ${ }^{1}$ For Space Shuttle Orbiter reentry, transition typically occurs late in the trajectory, when the vehicle is already at Mach 10 or below. ${ }^{2}$ However, protruding elements on vehicle exterior, such as gap fillers, uneven tiles or components of a tile repair may cause an early transition resulting in excessive heating that may compromise the thermal protection system. ${ }^{3}$ The time of transition and extent of augmented heating generally depend on the trip height, geometry and location on the vehicle.

\footnotetext{
* Aerothermal Engineer, Aerothermal and Flight Dynamics, 2224 Bay Area Blvd, Houston, TX 77058/Mail Stop JE-B3-2.

† Aerothermal Engineer, Aerothermal and Flight Dynamics, 2224 Bay Area Blvd, Houston, TX 77058/Mail Stop JE-B3-2, Member AIAA.

¥ Aerospace Engineer, Shuttle Aeroheating, 5301 Bolsa Ave, Huntington Beach, CA 92647/MailCode: H012-C248, Senior Member AIAA.

§ Aerothermal Engineer, Applied Aerosciences and CFD Branch, 2101 NASA Pkwy., Houston, TX 77058/Mail Stop EG3, Associate Fellow AIAA.

** Aerospace Engineer, Materials and Processes Branch, 2101 NASA Pkwy., Houston, TX 77058/Mail Stop ES3.

†† Aerospace Engineer, Materials and Processes Branch, 2101 NASA Pkwy., Houston, TX 77058/Mail Stop ES3.

¥ Aerospace Engineer, Materials and Processes Branch, 2101 NASA Pkwy., Houston, TX 77058/Mail Stop EG3.

$\S \S$ Senior Research Scientist, Aerothermodynamics Branch, Hampton, VA 23681/Mail Stop 408A.
}

1

American Institute of Aeronautics and Astronautics 
The Boundary Layer Transition flight experiment (BLT FE) ${ }^{4,5}$ was designed to address early transition and characterize heating augmentation on the trip as well as the downstream surfaces in flight. The experiment used a specially manufactured protuberance of a certain height and geometry installed in a specific location on the Space Shuttle Orbiter windward side to trip the boundary layer at a targeted Mach number point of re-entry trajectory. The trip height would be different each flight. The STS-119 and STS-128 missions were the first two flights that carried BLT FE protuberances of 0.25 and 0.35 inches tall, respectively.

Prior to these flights, a series of arc-jet tests was conceived at NASA Johnson Space Center's (JSC) Atmospheric Reentry Materials and Structures Facility (ARMSEF) pursuing the following main objectives:

1. Investigating heating augmentation on the protuberance and downstream tile acreage while demonstrating the protuberance ability to withstand the Orbiter flight-like re-entry heating environments at the BLT FE hardware location on the vehicle;

2. Investigating heating augmentation on the protuberance and downstream tile acreage while demonstrating the protuberance failure mode by exposing it to a supersonic flow of high-enthalpy air.

The flight-like environments required that the arc-jet flow remained predominantly laminar while matching the flight smooth outer mold line (OML) surface temperature and matching or exceeding the expected levels of total enthalpy at protuberance tip.

Demonstration of the protuberance failure mode required exceeding the material slumping limit for a considerable amount of time. The laminar flow requirement was dropped. Changes to the arc heater configuration and alternate means of increasing the tile specimen surface temperature were considered.

This paper provides an overview of the arc-jet test setup, protuberance test models and test conditions, discussion of the arc-jet test results, including heating augmentation bump factors on the protuberance and downstream acreage tiles observed, as well as comparison with computational fluid dynamics (CFD) predictions and limited flight data.

\section{Test Facility}

The JSC arc-jet test facility was first described in $1983 .^{6}$ There are two test positions. Test position one (TP1) is the channel nozzle arc-jet which is used to study flat surface heat transfer at zero angle of attack. Test position two (TP2) is the conical nozzle arc-jet which is used to study heat transfer to various blunted bodies (e.g., wedges, spheres) and small flat plates at 0 to 45 -degree angles of attack. Each test position includes a $10 \mathrm{MW}$ arc heater and a 12-ft dia. test vacuum chamber with a diffuser. A solid-state power supply; water cooling system; boiler, 4-stage steam ejector system; vacuum pumping system; test gas supply system; control room; and data room are common and can serve either test position. ${ }^{6}$

The arc heater of either TP1 or TP2 contains a multi-pack dual-diameter constricted arc column. A tungsten cathode is used as the upstream electrode, and a conical copper anode is used as the downstream electrode. The arc heater contains a variable number of individually water-cooled and electrically insulated constrictor segments assembled in modular packs, $18-20$ segments each. ${ }^{6}$ The number of packs in the arc heater may vary from 5 to 14 to achieve various levels of gas bulk enthalpy. This test program used the arc heater configurations with 10 and 14 packs.

The vacuum chamber can maintain a residual pressure of 120-300 microns $\mathrm{Hg}$, which corresponds to approximately 204,000-182,000 feet of altitude, respectively. The vacuum chamber pressure varies during tests depending on the test gas flow rate.

The typical test gas is synthetic air, which is a mixture of $77 \% \mathrm{~N} 2$ and $23 \% \mathrm{O} 2$ by mass. It is injected in multiple locations throughout the arc column and sometimes in the plenum. Nitrogen is always injected in the vicinity of the tungsten cathode to suppress its oxidation.

The TP1 is configured with a 2 -inch wide rectangular channel nozzle expanding

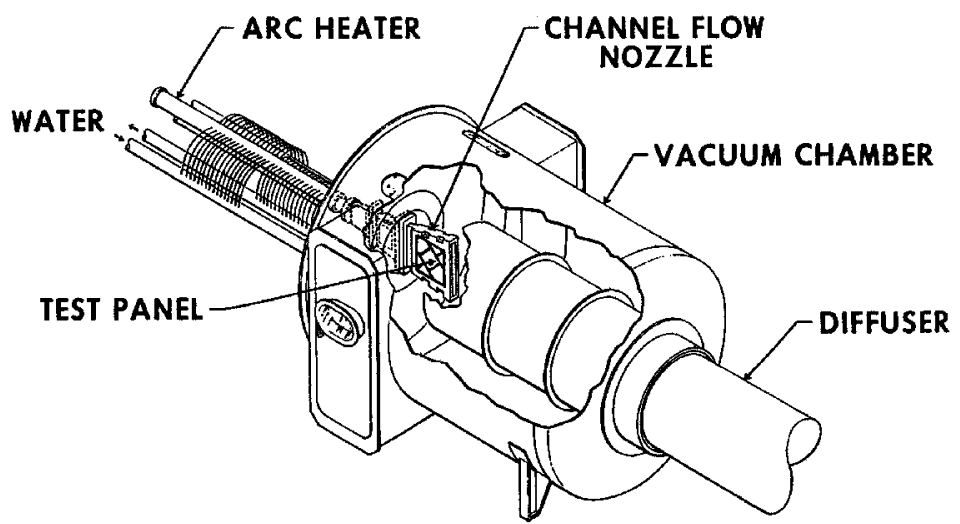

Figure 1. Rectangular channel nozzle test technique. ${ }^{6}$ 
from a $2 \times 2$-inch throat at a $10^{\circ}$ half angle and can accommodate flat plate specimens as large as $24 \times 24$ inches. The channel nozzle arc-jet has two test sections, $12 \times 12$ inch and $24 \times 24-$ inch. $^{6}$ Flat plate specimens are mounted in these test sections from either side of the nozzle and set flush with the channel interior walls. The sections that are not used for data gathering during a given test have water-cooled doors installed.

An isometric sketch of a typical channel nozzle test technique is presented in Fig. 1, showing the arc heater, nozzle, vacuum chamber, diffuser, and a Reusable Surface Insulation (RSI) test panel installed inside the chamber. ${ }^{6}$ Figure 2 presents a recent photograph of TP1 showing the vacuum chamber and the arc heater with gas and cooling water lines attached. ${ }^{7}$

Because the Orbiter surface in the vicinity of the BLT FE location is flat, ${ }^{5}$ the

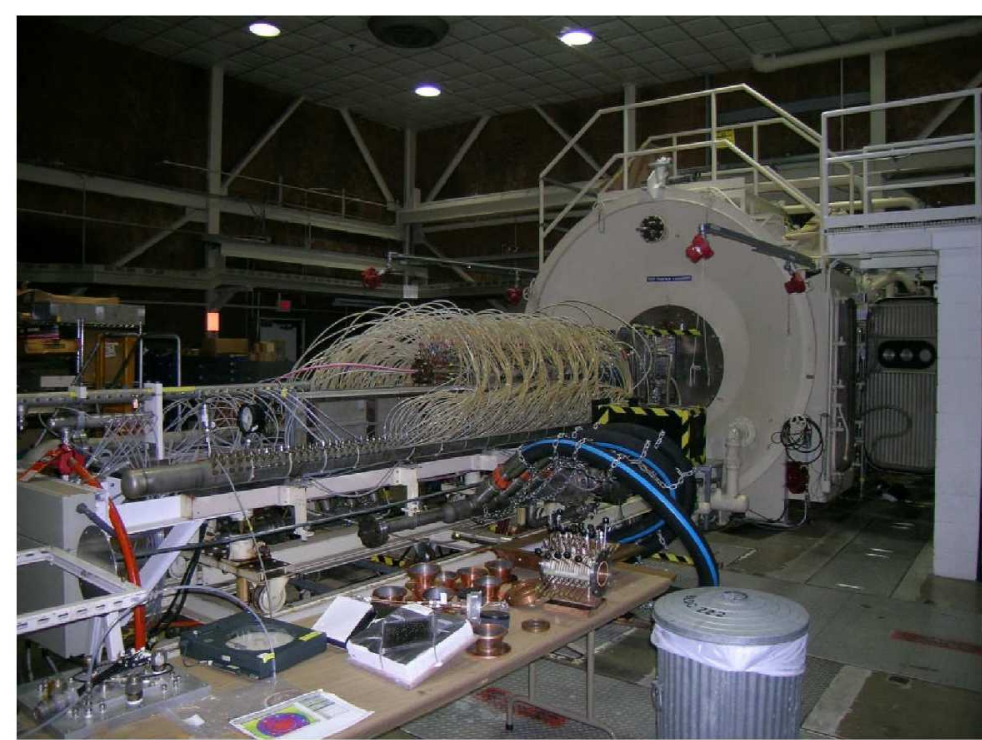

Figure 2. Photograph of TP1 showing components of the arcjet facility. ${ }^{7}$ TP1 channel nozzle apparatus was chosen for this test program. The typical Orbiter tile surface temperatures at that location during re-entry suggested that BLT arc-jet tests were to be conducted in the $24 \times 24$-inch test section.

\section{Test Models, Setup and Instrumentation}

Fin-shaped 4-inch long protuberances of two heights ( 0.25 and 0.35 inches) were tested. Each protuberance was fabricated as an integral part of a $6 \times 6$ inch tile insert made of Boeing Rigid Insulation (BRI-18) material and coated with Reaction Cured Glass (RCG), the black coating used for the Shuttle Orbiter windward surfaces. The protuberance shape went through several design iterations before it arrived at its final revision (Fig. 3). A total of seven such tile inserts were manufactured: four with the 0.25 -in. trip height, and three with the 0.35 in. trip height. A 3D pre-test surface scan of the 0.35 -inch protuberance tile insert is presented in Fig. 3 to illustrate the forward facing protuberance surface.

A $2 \times 2$-foot variable configuration tile

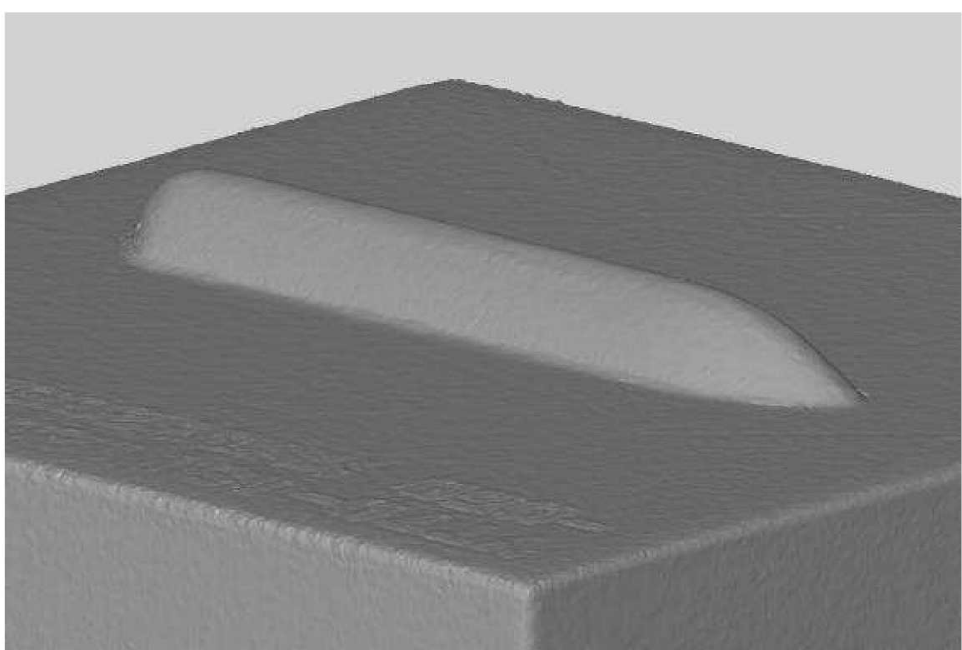

Figure 3. Boundary layer trip protuberance. ${ }^{8}$ array (VCTA) was used as a carrier for the protuberance tile inserts. It allowed for quick in-situ replacement of the protuberance models without dismounting the whole array. The VCTA tiles were Lockheed Insulation (LI-900). Later on in the test program three downstream tiles were replaced with higher density LI-2200 tiles that could better withstand elevated heating levels.

The protuberance tile inserts were installed in the tile array such that the protuberance forward surface (a larger radius of curvature) faced the flow at a 45-degree sweep angle to resemble the protuberance orientation with respect to the local stream line in flight.

The protuberance test models and VCTA were equipped with surface, sidewall and bond line thermocouples. Type R thermocouples capable of reading temperatures as high as $3200 \mathrm{deg} F$ were used for surface and sidewall measurements. Type $\mathrm{K}$ thermocouple were used for the bond line measurements and covered a temperature range of up to $2490 \mathrm{deg} \mathrm{F}{ }^{9}$ Including the data acquisition system, the total temperature measurement uncertainty in these 
tests did not exceed $\pm 2 \%$ of the measured value for both surface and bondline thermocouple locations. ${ }^{8}$ X-ray images of the protuberance tile inserts were taken prior to tests to visually check the surface thermocouple proximity to surfaces.

Locations of surface thermocouples are marked in Fig. 4. The reference OML thermocouple (TCH4) was part of the VCTA instrumentation. It was located in the undisturbed flow region sufficiently upstream of the protuberance leading edge.

Tempilaq(i) temperature-indicating paint was applied to the corner tiles of the array in locations that were unlikely to see flow disturbances from the protrusion. Five different grades of paint that melt at different temperatures between 1500 and 2000 deg $F$ were used. The intent of using the paint was to obtain another indication of the smooth RCG-coated tile surface temperature, as well as determine the usefulness of such paint for the flight experiment.

\section{Test Conditions}

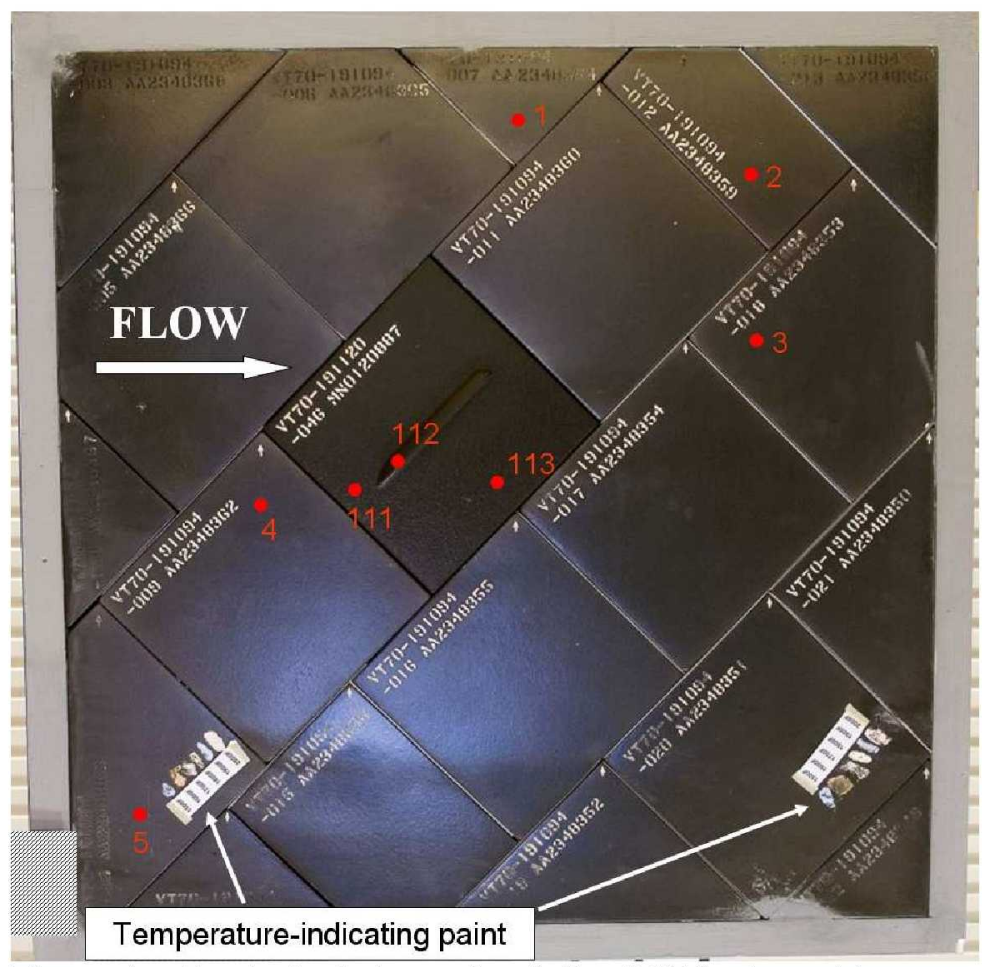

Figure 4. Pre-test photograph of the 0.25-inch protuberance installed in the variable configuration tile array.

Arc-jet test conditions are typically expressed in terms of test gas flow rate and arc current. Different approaches of selecting test conditions were applied to each of the two main objectives of this test series.

\section{A. Flight-Like Re-Entry Heating}

The flight-like environments for the protuberances were generated in the arc-jet by keeping in mind the following three conditions: 1) laminar flow upstream of the protuberance, 2) flight-like smooth OML tile surface temperatures, and 3) flight-like level of total enthalpy at the protuberance tip. The flight-like temperatures and enthalpies were tied to the BLT FE location on the vehicle. A 10-pack arc heater configuration was primarily used for the 0.25-inch tall protuberance, and a 14-pack arc heater configuration was used for the 0.35 - inch protuberance only. Pre-test analytical evaluation of flight and arc-jet environments helped narrow down the circle of candidate test conditions which made calibration test runs significantly more effective.

Review of the channel nozzle arc-jet test data from previous test programs ${ }^{7}$ suggested a number of heater regimes that produce a smooth tile surface temperature at the $24 \times 24$-inch test section in the 1500-1800 deg F range, characteristic of the Orbiter re-entry environment at the BLT FE location on the wing. An assumption for turbulent transition onset in the channel nozzle's $24 \times 24$-inch test section ${ }^{6}$ was used to limit the candidate test conditions to a mass flow rate below $0.4 \mathrm{lbm} / \mathrm{sec}$.

The flight-like levels of total enthalpy for various protuberance heights were extracted from eleven flight Shuttle Orbiter CFD solutions covering the Orbiter re-entry trajectory from Mach 25 to Mach $10{ }^{8}$ The expected arc-jet total enthalpy levels at the protrusion tip for each candidate test condition were compared to the flight values to establish the flight coverage by the arc-jet (Table 1). The arc-jet boundary layer profiles of total enthalpy sampled from respective CFD solutions looked typical for hypersonic air flows, and were therefore assumed to

Table 1. BLT FE flight Mach number ranges covered by the arc-jet conditions.

\begin{tabular}{|c|c|c|}
\hline Target cond. & \multicolumn{2}{|c|}{ Mach numbers covered } \\
\hline (deg F) & 0.25 -inch trip & 0.35 -inch trip \\
\hline 1200 & 12 & 16 \\
\hline 1500 & 18 & 25 \\
\hline 1600 & 18 & -- \\
\hline 1700 & 20 & 25 \\
\hline 1800 & 25 & -- \\
\hline 2000 & 25 & 25 \\
\hline
\end{tabular}

4

American Institute of Aeronautics and Astronautics 
be similar to each other across all of the channel nozzle flow regimes. Due to a large number of candidate test conditions, the momentum thickness for each condition was initially assessed with the inviscid flow expansion methodology, ${ }^{10}$ and then translated into a boundary layer thickness using Eq. (1).

$$
\delta_{B L}=7.975 \cdot \theta
$$

The correlation in Eq (1) was anchored to a limited number of channel nozzle arc-jet CFD solutions available at the time. ${ }^{11,8}$ Attention was paid to ensure that the flow is not fully developed at the $24 \times 24-$ inch test section for each test condition and the boundary layer thickness is less than 1.0 inches.

The requirement of matching the protuberance tip enthalpy was dropped for the 14-pack arc heater configuration. The laminar flow field requirement kept the mass flow rate low and the arc heater regimes that produced the desired smooth OML temperatures were found during calibration runs.

\section{B. Protuberance Failure Mode}

Demonstration of the protuberance failure mode required that the material slumping limit (around $2900 \mathrm{deg}$ F) was exceeded for a considerable amount of time during the test. The laminar flow requirement was dropped. Environments were no longer linked to the BLT FE location on the vehicle. This portion of the test program focused on the 0.35 -inch protuberance model with protuberance tip temperature being the main target. Test conditions were calibrated with protuberance

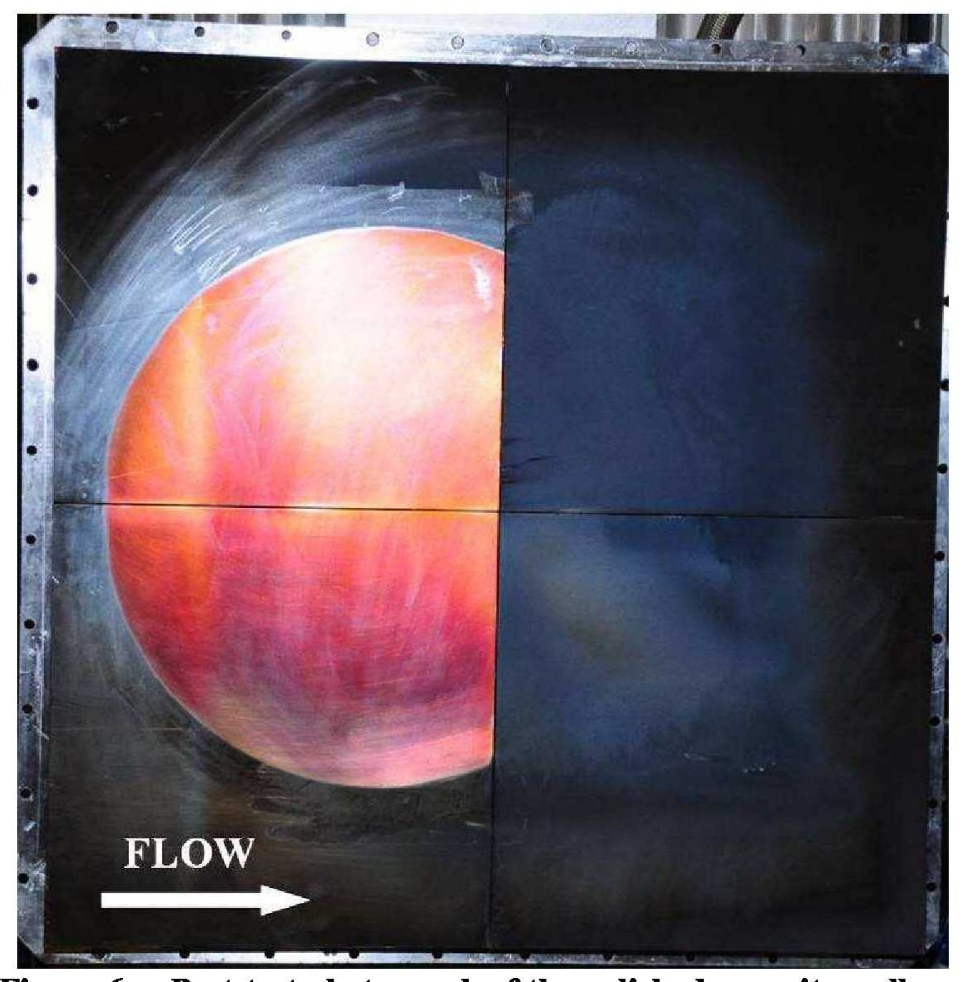

Figure 6. Post-test photograph of the polished opposite wall.

model installed in place. As the tests progressed from lower to higher heating conditions, protuberance temperature data were extrapolated to guide the condition selection for the subsequent test run. The arc heater was re-configured from 10 to 14 packs. In order to further increase the tile specimen surface temperature a polished opposite cold wall was used (as suggested in Reference 6). Care was exercised in defining the exact region of the opposite cold wall that needed to be polished (Fig. 6). A time limit was applied to the test duration at the condition that exceeded the protuberance material slumping limit so as to preserve the rest of the VCTA acreage for future tests.

Further discussion of the test conditions used in this portion of the tests is provided in the results section below.

\section{Results and Discussion}

\section{A. Calibration Runs}

Before any protuberance tests, calibration runs with a smooth tile array were performed. An old cavity heating test model was installed in place of the protuberance tile insert. The TC\#4 reference surface thermocouple (Fig. 4) was used to monitor the smooth OML tile surface temperature to match the target value. For the 10-pack arc heater the calibration established the test conditions with smooth OML temperature of 1200,1500,1600, 1700, and 1800 deg F. The $1200 \mathrm{deg} F$ condition was treated as a warm-up step in order to approximate the heating early in re-entry trajectory. An additional test condition (2000 deg F) was established later during one of the protuberance runs as an attempt to emulate the turbulent portion of the Orbiter re-entry at the BLT FE location. The 14-pack arc heater calibration runs established only the 1500, 1700, and $2000 \mathrm{deg}$ F smooth OML temperature test conditions.

\section{B. Test Runs With 0.25-inch Protuberance}


The 0.25 -inch protuberances were tested with a 10 -pack arc heater configuration only. No special methods were used to further increase heating to the test model. A total of three test runs with the 0.25 -inch protuberances were conducted. Each run used a schedule of test conditions, called a test profile. Each test condition (step) in a profile is assigned with a hold time, or duration, within which it is held constant. The step-wise test profiles for the 0.25 -inch protuberance are listed in Table 2 . Transition between steps typically occurs quickly, within 2-4 seconds. The last test profile in Table 2, however, executed transitions between steps gradually in order to avoid spikes in protuberance heating. Such heating spikes would be of temporary nature and may cause protuberance material failure that would have not happened had the heat flux been raised gradually.

Table 2. Test profiles for the 0.25 -inch protuberance model.

\begin{tabular}{|c|c|c|c|}
$\begin{array}{c}\text { Target } \\
\text { temperature }\end{array}$ & $\begin{array}{c}\text { Test } \\
\text { Profile } \\
1\end{array}$ & $\begin{array}{c}\text { Test } \\
\text { Profile } \\
2\end{array}$ & $\begin{array}{c}\text { Test } \\
\text { Profile } \\
3\end{array}$ \\
\hline deg F & sec & sec & sec \\
\hline 1200 & 100 & 100 & 90 \\
\hline 1500 & 200 & 200 & 190 \\
\hline 1600 & 200 & - & - \\
\hline 1700 & 200 & 200 & - \\
\hline 1800 & - & 200 & 210 \\
\hline 2000 & - & - & 210 \\
\hline 2000 & - & - & 130 \\
\hline
\end{tabular}

The post-test examination of the protuberance model revealed no signs of tile material or RCG coating failure. Both protuberance and downstream acreage temperatures were within the acceptable limits. The highest temperature achieved on the protuberance tip was $2250 \mathrm{deg}$ F. The characteristic temperatures observed in the $0.25-$ inch protuberance tests are summarized in Table 3.

Table 3. Characteristic temperatures observed in the 0.25 -inch protuberance tests.

\begin{tabular}{|c|c|c|c|c|c|}
\hline \multirow{2}{*}{$\begin{array}{c}\text { Target } \\
\text { Temperature }\end{array}$} & Reference & \multicolumn{2}{|c|}{ Protuberance } & \multicolumn{2}{|c|}{ Downstream tile } \\
\cline { 3 - 6 } & Temperature & Temperature & $\begin{array}{c}\text { Heat flux } \\
\text { bump factor }\end{array}$ & Temperature & $\begin{array}{c}\text { Heat flux } \\
\text { bump factor }\end{array}$ \\
\hline deg F & deg F & deg F & & deg F & \\
\hline 1600 & 1592 & 1787 & 1.439 & 1633 & 1.083 \\
\hline 1800 & 1796 & 2108 & 1.678 & 1944 & 1.288 \\
\hline
\end{tabular}

The heating bump factors for protuberance and downstream tile presented in Table 3 were calculated based on the method of a single reference location and used Eq. (2):

$$
B F=\left(\frac{T\left({ }^{\circ} R\right)}{T_{r e f}\left({ }^{\circ} R\right)}\right)^{4}
$$

The mean heating bump factors for the 0.25 -inch protuberance constituted 1.52 and 1.16 for the downstream tile. The corresponding CFD-predicted heating bump factors were found to be significantly higher (2.94 and 1.79, respectively). ${ }^{11}$

The early experience with the temperature-indicating paint was discouraging. After the test there was still a residue from the paint smeared in the downstream direction. Application of the paint was difficult because the mixture was very viscous with large lumps of the solute unmixed within the solvent. The failure of the paint to perform as expected in the tunnel could be because the sample coat was too thick for the levels of shear in TP1. 


\section{Test Runs With 0.35-inch Protuberance}

A total of four test runs were conducted with the 0.35 -inch protuberances, one with the 10-pack and three with the 14-pack arc heater configuration. Because the key concept of this part of the test program was reaching and exceeding the protuberance slumping limit, the protuberance temperature was of most importance and therefore closely monitored. The laminar flow requirement was not critical at that point, and was dropped.

Along with the increase of arc heater length, higher flow rates and polishing of the opposite cold wall were also used to increase protuberance tip temperature. Table 4 below provides a summary of the test profiles for the 0.35 inch protuberance.

Table 4. Test profiles for the 0.35 -inch protuberance model.

\begin{tabular}{|c|c|c|c|c|c|c|}
\hline \multicolumn{2}{|c|}{ Target temperature } & $\begin{array}{c}\text { Arc Heater } \\
\text { Packs }\end{array}$ & $\begin{array}{c}\text { Test } \\
\text { Profile } \\
1\end{array}$ & $\begin{array}{c}\text { Test } \\
\text { Profile } \\
2\end{array}$ & $\begin{array}{c}\text { Test } \\
\text { Profile } \\
3\end{array}$ & $\begin{array}{c}\text { Test } \\
\text { Profile } \\
4\end{array}$ \\
\hline \multicolumn{2}{|c|}{ deg F } & & sec & sec & sec & sec \\
\hline OML & Protuberance & & 10 packs & \multicolumn{3}{|c|}{14 packs } \\
\hline $1200 \pm 25$ & & 14 & - & 25 & - & - \\
\hline $1500 \pm 25$ & & 10 & 130 & - & 30 & 30 \\
\hline $1500 \pm 25$ & & 14 & - & 200 & - & - \\
\hline $1700 \pm 25$ & & 14 & - & 600 & - & - \\
\hline $1800 \pm 25$ & & 10 & 220 & - & - & - \\
\hline $2000 \pm 25$ & & 10 & 320 & - & - & - \\
\hline & $2400 \pm 25$ & 14 & - & - & 30 & - \\
\hline $2000 \pm 25$ & & 14 & - & 100 & 60 & - \\
\hline & $2600 \pm 25$ & 14 & - & - & 40 & - \\
\hline & $2700 \pm 25$ & 14 & - & - & 40 & - \\
\hline & $2900 \pm 25$ & 10 & 55 & - & - & - \\
\hline & $2900 \pm 25$ & 14 & - & - & 40 & - \\
\hline & $3100 \pm 100$ & 14 & - & - & 40 & 490 \\
\hline
\end{tabular}

The opposite cold wall was polished for the profiles 1 and 4 to reflect some of the heat flux radiated by the test model back onto it. The technique was reliable in raising test model surface temperatures; however, the best method to account for the temperature increase in the pos-test data processing requires further investigation.

The test profile run with a 10-pack heater and a polished opposite wall generated just enough heating to the protuberance tip to produce a slumping onset. The post-test inspection revealed discoloration and some melting of RCG coating that partially exposed the protuberance thermocouple bead (Fig. 7). Figure 8 illustrates the amount of flattening of the protuberance tip characterized by the posttest analysis of the test model surface scans. ${ }^{8}$ The pre-test and post-test slices of the model

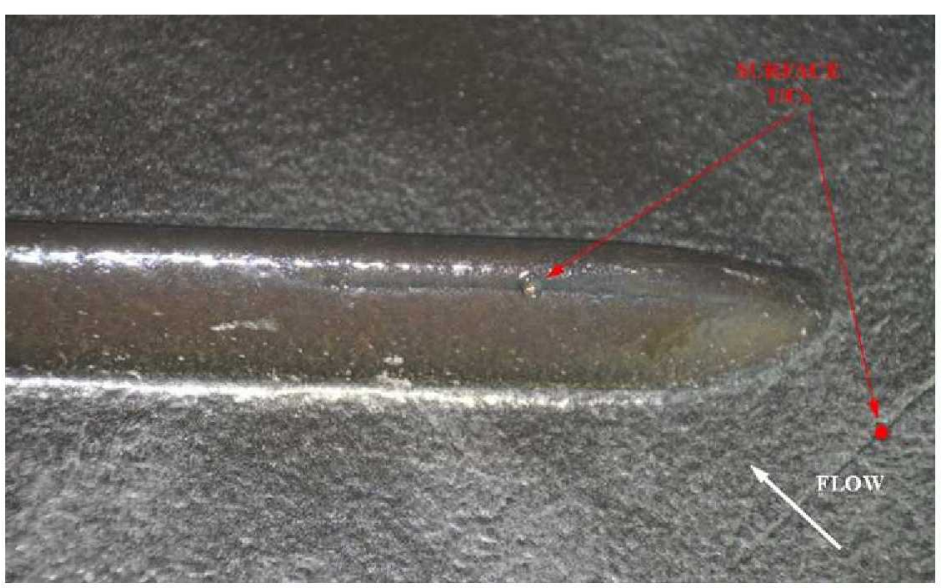

Figure 7. Post-test photograph of the 0.35-inch protuberance showing RCG coating discoloration and partially exposed thermocouple bead. surface scans were taken at an angle most suitable to best illustrate the shape change. 
Test profile 2 (Table 4) exposed the 0.35 inch protuberance to the flight-like environments in order to demonstrate its survival and assess the heating augmentation on the protuberance tip and downstream acreage. The post-test visual inspection found no sign of damage to the protuberance or the tile array. The characteristic temperatures from that and other test runs with the 0.35 -inch protuberance are presented in Table 5.

The protuberance material slumping limit condition was re-created with the 14-pack heater configuration without the opposite wall being polished using test profile 3 (Table 4). A post-test photograph of that protuberance trip is shown in Fig. 9.

Polishing the opposite cold wall for test profile 4 resulted in an approximately 100 150 deg $F$ increase in surface temperature which turned out sufficient enough to effectively demonstrate the protuberance failure mode. The protuberance

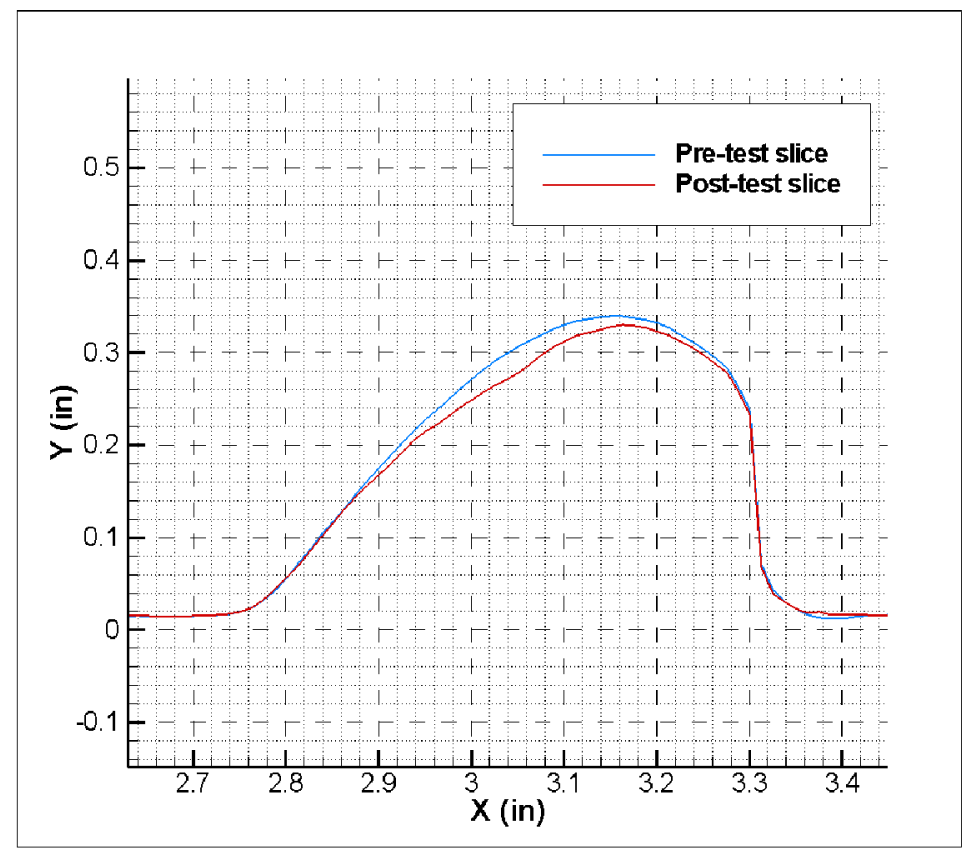

Figure 8. Protuberance shape change.

thermocouple was lost 180 seconds into the test run. Monitoring the temperature difference between the upstream and the downstream smooth OML thermocouple suggested that the run be terminated at 520 seconds in order to prevent the possible overheating damage to the rest of the VCTA. Figure 10 illustrates the post-test condition of the protuberance trip. Along with the deformed protuberance shape, a scorch mark on the RCG coating can be seen downstream of the protuberance.

Polishing the wall opposite to the tile array raised heating to the test model by $7-23 \%$ depending on location of the particular thermocouple used for comparison. It is believed that the reflected heat flux effect may be accounted for as a fraction of total heating at a given location on the tile array. If this approach holds true, the heating bump factors derived from tests would be insensitive to the magnitude of reflected heat flux.

Table 5. Characteristic temperatures from the 0.35 -inch protuberance tests.

\begin{tabular}{|c|c|c|c|c|c|}
\hline \multirow[b]{2}{*}{$\begin{array}{l}\text { Reference } \\
\text { Temperature }\end{array}$} & \multirow[b]{2}{*}{$\begin{array}{l}\text { Opp. Wall } \\
\text { Polishing }\end{array}$} & \multicolumn{2}{|c|}{ Protuberance } & \multicolumn{2}{|c|}{ Downstream tile } \\
\hline & & Temperature & $\begin{array}{l}\text { Heat flux } \\
\text { bump factor }\end{array}$ & Temperature & $\begin{array}{l}\text { Heat flux } \\
\text { bump factor }\end{array}$ \\
\hline $\operatorname{deg} F$ & & $\operatorname{deg} F$ & & $\operatorname{deg} F$ & \\
\hline \multicolumn{6}{|c|}{ With the opposite cold wall darkened } \\
\hline 1879 & $\mathbf{N}$ & 2272 & 1.86 & 1938 & 1.10 \\
\hline 2108 & $\overline{\mathbf{N}}$ & 2908 & 2.96 & 2299 & 1.33 \\
\hline \multicolumn{6}{|c|}{ With the opposite cold wall polished } \\
\hline 2071 & $\bar{Y}$ & 2583 & 2.09 & 2283 & 1.38 \\
\hline 2257 & $\bar{Y}$ & 2887 & 2.30 & 2472 & 1.36 \\
\hline
\end{tabular}

The heating bump factors for the 0.35 -inch protuberance showed a lot of scatter not only because of the polished opposite wall but also because of the high flow rate conditions. The mean heating bump factor constituted 2.34 for the protuberance and 1.16 for the downstream tile. The corresponding CFD-predicted heating bumn factors were found to be significantly higher $\left(4.14\right.$ and 1.84 , respectively $\left.{ }^{11}\right)$ yet within the range of test data. 


\section{Conclusions}

The flight-like environments for the 0.25 and 0.35 inch BLT protuberances were successfully reproduced in the JSC channel nozzle arc-jet.

Both protuberances survived these flight-like environments with no visual damage to the tile surfaces. Surface and bondline temperatures of the tiles immediately downstream of the protuberance were well within acceptable limits.

Testing protuberances in the channel nozzle arc-jet is associated with generation of a series of shocks deflected by the protuberance and impinging onto the opposite wall of the channel. No thermal issues of the opposite wall heating were observed within the range of test environments and protuberance heights used.

Polishing of the cold wall opposite to the tile array resulted in $10-20 \%$ increase of heating to the test model. This technique produced heating augmentation every time it was used, and therefore, it can be deemed reliable, although care needs to be exercised if accounting for the reflected heat flux is required in the post-test analysis.

The 0.25 -inch trip arc-jet tests showed $25-30 \%$ lower heating bump factors compared to those seen in flight ${ }^{5}$ for both the protuberance and downstream tile acreage.

Arc-jet $\mathrm{CFD}^{11}$ predicted $60-95 \%$ higher protuberance and downstream acreage heating bump factors than those derived from test. Although CFD predictions were closer to the test data with the taller ( 0.35 -inch) protuberance, further investigation of this matter is needed to better understand the cause for a large CFD-to-test discrepancy.

The protuberance material failure (slumping)

limit was confirmed in test to be around 2900 deg F. Surpassing that limit by approximately 100 deg F was achieved with the 0.35 -inch protuberance by installing a polished cold wall opposite to the test article.

The protuberance material failure mode did not involve unzipping or tunneling effects. The downstream acreage tile temperatures were well within acceptable limits.

The temperature-indicating paint did not provide a consistent correlation with the thermocouple readings, and therefore its use in the arc-jet environments was considered unsuccessful.

\section{Acknowledgments}

The authors would like to thank the JSC ARMSEF personnel for excellent conduction of the tests, and great help with consolidation of test data, photographs, and instrumentation specifics. Pre- and post-test protuberance 3D surface scans were generated by Capture 3D, Inc. (Webster, Texas). The post-test protuberance recession examination was performed by Mike Horsley (The Boeing Company, Huntington Beach, California) and Emily Bulot (Texas A\&M University Intern, Engineering and Science Contract Group, Houston, Texas). The flight-like expected levels of total enthalpy at various protuberance heights were provided by David Saunders (ELORET Corporation, Sunnyvale, California). 


\section{References}

${ }^{1}$ Hollis, B.R., Berger, K.T., Horvath, T.J., Coblish, J.J., Norris, J.D., Lillard, R.P., and Kirk, B.S., "Aeroheating Testing and Predictions for Project Orion Crew Exploration Vehicle," J. of Spacecraft and Rockets, Vol. 46, No. 4, Jul.-Aug. 2009.

${ }^{2}$ Goodrich, W.D., Derry, S.M, Bertin, J.J. "Shuttle Orbiter Boundary-Layer Transition: A Comparison of Flight and Wind Tunnel Data", AIAA-83-0485, 21st AlAA Aerospace Sciences Meeting, Reno, Nevada, 10-13 Jan. 1983.

${ }^{3}$ Horvath, T.J., Berry, S.A., Merski, N.R., Berger, K.T., Buck, G.M., Liechty, D.S., and Schneider, S.P., "Shuttle Damage/Repair from the Perspective of Hypersonic Boundary Layer Transition - Experimental Results", AIAA-2006-2919, 9th AIAA/ASME Joint Thermophysics and Heat Transfer Conference, San Francisco, California, 5-8 Jun. 2006.

${ }^{4}$ Campbell, C.H., Garske, Kinder, G.R., Berry, S.A. "Orbiter Entry Boundary Layer Flight Testing", AIAA-2008-635, 46th AIAA Aerospace Sciences Meeting and Exhibit, Reno, Nevada, 7-10 Jan. 2008.

${ }^{5}$ Anderson, B.P., Campbell, C.H., Saucedo, L.A., Kinder, G.R., Burger, K.T., "BLT Flight Experiment Overview and In- Situ Measurements", AIAA-2010-0240, 48th AIAA Aerospace Sciences Meeting, Orlando, Florida, 4-7 Jan 2010.

${ }^{6}$ Rochelle, W.C., Battley, H.H., Grimaud, J.E., Tillian, D.J., Murray, L.P., Lueke, W.J., and Heaton, T.M., "Orbiter TPS Development and Certification Testing at the NASA/JSC $10 \mathrm{MW}$ Atmospheric Reentry Materials and Structures Evaluation Facility," AIAA-83-0147, 21st AIAA Aerospace Sciences Meeting, Reno, NV, 10-13 Jan. 1983.

${ }^{7}$ Larin, M.E., Marichalar, J. J., Fredo, J.A., Rochelle, W.C., "Results of Calibration Tests in Channel Nozzle of JSC Arc-Jet Facility", Lockheed Martin Space Operations, Report JSC-62673/LMSEAT-34416, Houston, Texas, Aug. 2004.

${ }^{8}$ Larin, M.E., Bulot, E.M., Schoolmeyer, W.H. "Boundary Layer Transition Trip HRSI TPS Tests at NASA JSC Arc-Jet Facility", Jacobs Technology/ESCG, Report JSC-64650/ESCG-4380-09-AFD-DOC-0009, Houston, Texas, Sept. 2009.

9"Practical Thermocouple Temperature Measurements", Dataforth Corp., Application Note AN-107, www.dataforth.com.

${ }^{10}$ Bade, W.L. and Yos, J.M., "The NATA Code - Theory and Analysis," NASA CR-2547, Jun. 1975.

${ }^{11}$ Marichalar, J.J., Larin, M.E., Campbell, C.H., Pulsonetti, M.V. "Boundary Layer Protuberance Simulations in Channel Nozzle Arc Jet”, AIAA-2010-0458, 48th AIAA Aerospace Sciences Meeting, Orlando, Florida, 4-7 Jan. 2010. 